\title{
LA REPRESIÓN DEL BWITI EN LA GUINEA ESPAÑOLA: EL CASO DE FERNANDO POO (1939-1962)
}

\author{
Jesús SÁNCHEZ AZAÑEDO 269 \\ Centro de Estudios Afro-Hispánicos
}

Resumen: Este trabajo intenta aportar la totalidad de las "Palabras" referidas al Bwiti en Fernando Poo del Tribunal de Santa Isabel, durante el período desde 1939 hasta 1962. La exposición cronológica de las mismas, nos permitirá ver el proceso de implantación del culto y su posterior desarrollo, confirmando su práctica en la isla. También pretendemos mostrar la represión ejercida contra sus practicantes, dando lugar en ocasiones a la persecución de familias muy concretas. Por último, queremos evidenciar cómo un documento del ańo 1939 en el que se piden medidas especiales para la represión del Bwiti, pudo ser programático en este sentido a la hora de aplicar las diferentes formas posteriores de represión del culto.

Palabras clave: Bwiti, Represión religiosa, Guinea Ecuatorial, Violencia jurídica, Colonialismo español, Cultos africanos.

AвsтRACT: The aim of this paper is to analyze all the "Palabras" regarding Bwiti which took place in the Tribunal de Santa Isabel of Fernando Poo between 1939 and 1962. By setting them out chronologically we will be able to see the process of implementation of the cult and its subsequent development, confirming its practice in the island. We also wish to show the repression suffered by the cult and its followers, which in some cases led to the persecution of particular families. Finally, we wish to prove how a document of 1939, which asks for special measures to be taken against Bwiti, was programmatic when it came to repressing the cult later on in various ways.

269 E-mail: s.a.jesus61@gmail.com 
KeYwords: Bwiti, Religious repression, Equatorial Guinea, Legal violence, Spanish colonialism, African cults.

\section{Introducción}

Los acercamientos a los diversos cultos dados durante su etapa colonial en Guinea Ecuatorial, son mas bien escasos, por no decir casi inexistentes. Si los cultos tradicionales de los Fang, los Bubis y otras etnias, sí que han recibido algún tratamiento, no podemos decir lo mismo sobre otros de nueva acuñación. Tanto el Bwiti como el Mbiri, los Hombres Leopardo y otros muchos, no han tenido prácticamente eco de aproximación alguna.

Dado el panorama de desolación académica respecto al tema, creemos de suma importancia retomar su investigación, y desde este énfasis abordamos el estudio de las relaciones jurídico-coloniales dadas con el Bwiti, sobre todo en su faceta más represiva. Pensamos que su aporte etnográfico es de suma utilidad, pues además de las responsabilidades académicas, el aporte documental que realizamos, sirve también de restitución y reconocimiento, tanto para aquellos que en su momento sufrieron las represiones, como para sus descendientes y demás guineanos de hoy en día.

Vista la sequía de estudios específicos sobre el fenómeno en la ex colonia, hemos tenido que acceder al estudio del mismo, desde las aproximaciones aportadas por la academia sobre zonas limítrofes; siendo éstas, junto a los aportes documentales, las que nos han permitido hacer un acercamiento paralelo teniendo en cuenta las coordenadas socio-culturales y político-económicas de Guinea.

La dificultad de acceso a la información institucional es mostrada por Fernández (1982), donde se lamenta de no poder dar ninguna estadística de la zona del Río Muni, por la represión que sufría el Bwiti desde la administración colonial española (p. 358).

La mayor expansión bwitista en Gabón es datada por Balandier (1970:23) entre 1920 y 1930, surgiendo ésta desde las filas de trabajadores, quienes se encargaron de difundir el nuevo culto cuando regresaban a sus lugares de origen. Es coincidente la aproximación de Fernández (1982:347-348), quién menciona en los inicios del s.XX, durante la Ia Guerra Mundial, testimonios de militancia 
en el nuevo culto de jóvenes que abandonaban el culto Biere tradicional. Esta datación es aplicable al caso guineano, pues tal como indica Leoncio Fernández (1927), la persecución del culto en el país vecino durante 1927 también supuso el cruce de fronteras hacia Guinea y el auge del mismo dentro de la ex colonia. (pp. 10-11). Nerín (2010) menciona la presencia de Bwiti en 1923, y cómo "algunos misioneros incluso lo confundían con el culto tradicional a los antepasados" (p. 288).

En general, para Tessmann (2003[1913]), Okenve (2007) y Nerín (2010), (1998), el comportamiento de los misioneros y la actitud de la Iglesia frente a los cultos nativos de la Guinea Española fueron poco tolerantes. Aparte de destruir todos los elementos materiales a los que tenían acceso de los diferentes cultos, de la "demonización" continua de los mismos y de su prohibición, la Iglesia instigaba en el mismo sentido a la administración colonial.

La convivencia interior de la colonia estaba afectada tanto por circunstancias más dilatadas en el tiempo, invasión extranjera -colonialismo español-, hambrunas, decrecimento demográfico, epidemias, como por otras dadas durante estas fechas, y cuya influencia se haría notar también en los nuevos cultos. En 1923 se produce el golpe de estado de Primo De Rivera, con el consiguiente cambio de gobernador para la colonia. Barrera y su política de atracción son sustituidos en 1925 por Núńez de Prado y su modelo represivo. A su vez, finalizada la conquista del Muni se daba un acceso más directo a braceros Fang para aportar mano de obra a Fernando Poo, siempre ávida de la misma.

Bajo este panorama se produjo la emergencia de cultos como el Bwiti. Éste, desde una reapropiación material y simbólica, supuso una renovación de materiales ya conocidos, pero reinterpretados en pós de una resistencia a la dominación, de un intento de comprensión de los cambios producidos en el seno de su sociedad, para retomar el sentido de los mundos vividos a partir de una transmutación de las antiguas solidaridades en otras de nuevo cuño. Esta reorganización cognitiva aportada por el Bwiti es dada de forma extática a través de la ingestión de Iboga, enteógeno que conecta con la "divinidad", produciendo su propia "visión" a cada uno de los adeptos que lo han ingerido. Pero el Bwiti es más que esto; para Aranzadi (2013), es: 
Rito de iniciación masculina(...)culto a los antepasados(...)sociedad secreta contra los brujos(...) disciplina de 'salus' (salud y salvación) entre los Fang(...) variante sincrética del cristianismo africano(...) producto exótico de consumo 'religioso' internacional New Age(...)una religión del Bosque y un legado de los Pigmeos. ( $\mathrm{p}, 90)$

La totalidad de la investigación ha sido realizada desde las aportaciones documentales sacadas del A.G.A. (Archivo General de la Administración) y está enfocada en cuatro puntos principales. Éstos serán presentados desde los propios casos (Palabras judiciales) ordenados cronológicamente.

Pretendemos mostrar, desde las propias Palabras, varias cosas: 1.La represión ejercida sobre el Bwiti; 2. La expansión desde la zona continental hacia la insular de cultos en principio propios del continente, llevados por los braceros migrantes; 3. La persecución y represión pública, concentrada en una serie de familias muy concretas (por sus prácticas y cultos no "ortodoxos"); 4. Cómo un documento de 1939 pudo dar origen de forma programática a las posteriores formas de represión de los cultos en la isla de Fernando Poo. 


\section{Las Palabras. Los casos}

Vamos a exponer la totalidad de las Palabras encontradas que hacen referencia directa al Bwiti. El orden cronológico de las mismas nos permitirá ver más claramente los procesos del culto y su desarrollo en Fernando Poo.

Año 1940:

En la (Palabra penal 380). (A.G.A.) (81/8533, Exp 380) Se produce en el poblado de Sácriba la primera referencia judicial a la práctica del Bwiti en Fernando Poo. El jefe de poblado Jose María Ondó, pedía la detención de Manuel Otogo, "vecino de Sacriba(...)natural de Bata", y de Ndongo Esono, bracero en Botonos. Ambos eran acusados y detenidos por su "dedicación de medicinas $<<B U E T I>>$ ".

Sentencia: un mes de cárcel para Manuel Otogo.

En la Pp814. (A.G.A.) (81/8533, Exp 814) Juan Nguema, de Kogo y Juan Ndongo, de Bata, eran detenidos y acusados por sus prácticas no acordes con las de las autoridades coloniales, ya que "hicieron medicina de Bueti(...) y por eso, que habiéndole dado la medicina le querian matar por Bueti".

El Bwiti no era censurado por su propia esencia sino por referencia a las enseñanzas católicas impartidas por los misioneros. El guardia colonial Enrique Aranda mostraba en carta manuscrita su postura: "Cosa que en mi demarcación no quiero por caso de que están tentando a los católicos para que no cumplan los mandamientos de ley católica".

Sentencia: "Un año de cárcel por hacer medicina del Mbueti. (para) Los indígenas Juan Nguema y Juan Ndongo" (Entre paréntesis mío).

Año 1941:

En la Pp 419. (A.G.A.) (81/8533, Exp 419) Aranda, realizaba detenciones en Botonos, había recibido una "comunicación de que por alli hacen el Bueti". También requisaba elementos de culto y rituales : "encontré al registrar la casa, la guitarra del Bueti, 1 gorra (con la) que suelen hacer el Bueti, 2 pastillas de blanco, y 2 pastillas de una sustancia roja". (Entre paréntesis mío). 
Sentencia: "Antonio Eya, Manuel Ela, Fernando Mbula-seis meses de cárcel y expulsión del territorio a su país, - Lucía Biyé, Magdalena Ngono, Josefa Nchama, Nobama Edú; tres meses de cárcel. -Todos ellos por pertenecer a la secta y practicar el Mbueti.

La Pp809. (A.G.A.) (81/8533, Exp 809) muestra una segunda detención en Laka. El bracero Domingo Nubi y el pescador Micha Nsue, ambos de Bata, eran acusados de "dedicarse a la práctica de medicina o <<buti>>". También les requisaban el arpa Ngombi y demás elementos rituales.

Sentencia: condenados a tres meses de cárcel, y con la declaración del presidente del tribunal: "defiendo cumplir esta condena en la Brigadía disciplinaria".

En la Pp819. (A.G.A.) (81/8533, Exp 819) se comunica cómo durante el día doce de Octubre, Bienvenido Arigo comandante del puesto de la demarcación de Basupú se encontraba con el cabo Alejandro Mbue y el sargento indígena de la Guardia Colonial Pedro Kunga. Éstos le informaban de las intolerables prácticas religiosas del "Buti" realizadas por Fabian Mesebe y Alfonso Gada Cobe. Tales prácticas eran tomadas por las autoridades coloniales como prohibidas y perjudiciales, pues eran de una religión que según las mismas autoridades iba "contra la católica" y se basaba y hacía "según manera antigua".

Sentencia: Desconocida y no encontrada en el expediente.

Año 1942:

En la Pp85.(A.G.A.) (81/8533, Exp 85) en Basupú, tras la reclamación contra su marido por malos tratos de la natural de Bata, Nchama Osa, quién contaba con el consejo de Simón Mangué y del gabonés Luis Ndongo, el Cabo requisaba sus elementos rituales, "los instrumentos del arte del Buiti" y arrestaba a ambos, éste por ser "maestro del Buiti”.

Sentencia: "Dos meses de Brigada al Luis Ndongo y tres a Simón Manguê".

Año 1946:

En la Pp42.(A.G.A.) (81/8553, legajo 42) un grupo de vecinos de Rebola demandaban a Antonio Nguema, Salvador Nguase y Alfonso Enkoni, natural de Bata y casado con la bubi Regina Etapa. Alfonso era propietario de sus fincas, 
y Nguase trabajaba legalmente de bracero con él. La demanda venía de deudas contraídas por los demandantes con los denunciados por servicios de curación, dando esto lugar a descubrir la existencia de prácticas bwitistas en Rebola.

Declaraba Nkoni, que: "Antonio Nguema y Salvador son los que se dedican para hacer el Buti(...)Ahi que todas las noches hacen butí(...) yo de mi parte, yo se todas las guitarras que suelen tocar cuando hacen sus medicamentos". A su vez, su esposa Regina diferenciaba las prácticas curativas de su esposo dedicadas a mitigar los dolores, de las de aquellos, "los que hacen el Embueti", como Nguema, que había sido visto en la preparación de "sus medicinas o la ceremonia llamada BUETP".

Sentencia: Alfonso Nkoni, Antonio Nguema y Salvador Nguase, 6 meses de cárcel, además, Alfonso con multa de 100 pesetas, y "50 palos" para Antonio y Salvador. Algunos vecinos deudores: "Pablo Boko, Francisco Bolasa y Mariano Sialo 50 pts de multa cada uno". El resto de deudores, Francisco Bolete, Mariano Sikobo y Antonio Leká, salían indemnes.

\section{Año 1947:}

En la Pp71.(A.G.A.) (81/8555, legajo penal 71) Antonio Nguema y Salvador Nguase seguían con sus prácticas, y de nuevo eran acusados.

María Alkala se oponía al matrimonio católico de su hija Paulina y Santiago Asumu. Junto a Nguema y Nguase presionaba a su hija contra la forma no tradicional de matrimonio. Ésta última demandaba a su madre: "recurro en SUPLICA se digne tener por presentada la presente instancia para proceder al embarque de mi madre para el continente a fin de que vaya a su pueblo en la zona francesa del Gabón".

Sentencia: "Asunto por medicinas de mbueti(...)comprobado que los demandantes pertenecen a la secta del Mbueti y(...)hacer medicina, acuerdo imponer a María Alkala, José Ndongo, Antonio Nguema y Salvador Ona, un año de cárcel (tras el cual) serán expulsados del pais". (Entre paréntesis mío).

En Agosto de este año sale a la luz un grupo numeroso de personas acusadas de prácticas bwitistas, éste estará activo durante años y con conexiones de alguno de los miembros (Saturnino Opo en 1944, y Pp 558) en Palabras anteriores al ańo 1947. Su actividad centrada en Laka, no impedía su gran movilidad territorial. 
En la Pp 174. (A.G.A.) (81/8556, legajo penal 174) el "Cabo(...) del destacamento de Laka", Alí Doso Sudán mostraba las actividades de un grupo de indígenas bubis, Saturnino Opo, Bernardo Ripen, Anastasio Beña, Cecilio Ripen, Justo Bosochi, Fernando Siale, Fernando Bolekio, Benino Titi y Carmelo Siale. Eran acusados por "medicineros" y de la muerte del niño Carlos Pelite. Quién había muerto finalmente tras haber sido intentada su curación mediante algún tipo de remedio mágico durante el transcurso de su enfermedad. Por último, eran requisadas "las cosas que tenían para emplear sus medicinas".

Sentencia:

Visto que el indígena Saturnino Opo, ha hecho medicina, en el niño Carlos Pelite, el cual falleció al día siguiente de tomar la misma, y aunque se ignore si dicha medicina haya podido influir en la muerte de dicho niño. Se acuerda imponer a dicho Saturnino un año de cárcel

por dedicarse a practicar la medicina y ser reincidente de dicha falta, ya que por esto mismo fue castigado en el año 1944 con un año de cárcel por la misma causa. Se le impone al indígena Bernardo Ripen un año de cárcel por habérsele encontrado en su poder un libro y objeto medicineros y dedicarse a practicar y explicar la medicina del país. Se le impone a Anastasio Beña tres meses de cárcel, por practicar la medicina. Se impone a Fernando Siale, Cecilio Ripen, Benigno Tito, Justo Bosochi y Carmelo Siale, quince días de cárcel por asistir a reuniones de medicina, practicada por los anteriores.

En la Pp178.(A.G.A.) (81/8556, legajo penal 178) de Septiembre, se produce una triple denuncia, del Cabo Alí Doso, de un anónimo, "el natural de Laka", y del claretiano "Padre Parrilla".

El "natural de Laka", daba gracias al Administrador territorial por "haber puesto en la cárcel a los naturales(...)por las tonterias de Butî", también denunciaba al jefe del poblado Bonifacio Lepa de ser cómplice de los integrantes del núcleo, mostrando el miedo de los vecinos del poblado hacia él y pidiendo su persecución legal. 
Las denuncias del Padre Parrilla, son tres. En una de ellas mostraba su favor hacia dos indígenas para que fuesen liberados y en las otras hacía extensa referencia a las actividades del grupo y el papel de cada uno de los acusados.

Alí Doso enviaba comunicación de sus pesquisas y detenciones. Remedios Enoté era interrogada "por el asunto de la Medicina del boti", declarando la participación de otras dos mujeres en el asunto, las cuales eran custodias de un libro, dando pie a Alí Doso para pedir el castigo de una de ellas: "es verdad, la Rosa sabe algo del libro de la medina del Boti".

Sentencia: "Se acuerda imponer, Justo Bosochi tres meses de cárcel, Asunción Barila seis meses, Pedro, Lorenzo y Cecilio Ripen 15 dias, Carlos Bechiro, Joaquin Say, Vicente Loeri en libertad y Raimundo Eriola en vigilancia. Se pone en libertad a Remedios"

Año 1949:

En la Palabra civil 229.(A.G.A.) (81/860, legajo 229), Alí Doso, desde Basakato del Este seguía con su cruzada particular. Palabra llena de acusaciones y contra acusaciones entre Bernardo Ripen y Lucas Bokusi, en la que Junto a la denuncia, Alí Doso adjuntaba "un comprobante hecho por el Rvdo padre Párroco del mismo Este (refiere a Basakato)". (En paréntesis mío). El comprobante, manuscrito pero sin firma, podemos afirmar que pertenece al Padre Parrilla ya que tiene la misma letra que las anteriores declaraciones manuscritas del mismo, lo que evidencia su autoría. Declaraba en tal manuscrito: "La gente, Señor, tiene mucho miedo a Bernardo Ripen porque está el primero de los del Mbueti”.

Alí Doso coincidía en su acusación:

Este Bernardo Ripen, ha sido uno de los que metieron en la cárcel, en 1947, cuando yo, el comandante que firma este escrito Alí Doso Sudán, desempeńaba sus servicios en Laka. El fue el maestro de la Medicina, denominada Mbutí; cual su mala conducta es reconocida por toda esta Administración. Un año de prisión, y sin corregirse. 
La presencia de Ripen en Cupapa, un poblado que no era el suyo, pero donde residía por entonces, debía estar provocando tensiones sociales, mostradas éstas en carta manuscrita del jefe del poblado, adjuntada en el expediente:

Para evitar desorden y la inmoralidad en el pueblo(...)solicitamos de V.S. lo que sigue. De acuerdo en la junta celebrada por el pueblo(...)que el llamado Bernardo Ripen, una vez cumplida esta su presente prisión, no vuelva más a pisar en este poblado, advirtiéndole para que vaya a su pueblo natal que es Baney Laka, porque ya no queremos saber nada de él.

Sentencia: "Por medicinero. Vista la Palabra y vistos los antecedentes que obran del llamado Bernardo Ripen, se acuerda imponerle dos meses de arresto".

Año1950:

En la Pp360.(A.G.A.) (81/8563, Exp 360), Miguel Esono Mangue declaraba al Cabo Gregorio Bibang, que "habia encontrado una escuadría de medicineros de Bueti”, siendo acusados por ésto, Ndongo Masa y Francisco Bras.

Sentencia: "Cárcel”.

Desde su aparición hacía diez años (véase la Pp380 de 1940), el Bwiti mantenía su presencia en Sácriba.

En la Pp636.(A.G.A.) (81/8565, Exp 636), el Cabo Gregorio Bibang comunicaba el 21 de septiembre: "se ha presentado(...)el jefe del poblado de Sácriba. Jose M. Ondo, manifestando que los vecinos de su pueblo llamados Antonio Engono, Ignacio Ayong, Jose Makanda y hermanos. Han presentado demanda contra él en el Patronato de Indígenas". Éstos pedían el cese de Ondó en la jefatura del poblado.

El 28 de noviembre, Ondó enviaba carta de renuncia al Administrador territorial en la cual quedaba patente, tanto la continuidad de las prácticas bwitistas, como la resistencia ejercida por parte de los integrantes del culto:

Hace cerca de DOCE AÑOS, que vengo desempeñando el cargo de jefe del poblado(...)y como sobre los esfuerzos que vengo empeńándome para la mejora de dicho poblado, los vecinos(...)me lo corresponden con ingratitud y disgustos censurándome en todos los conceptos, calificándome inmoral, injurias sobre injurias y maltratos de palabras y obras en chisterías; con el 
apoyo del (Embueti) que profesan mis adversarios(...)que quieren vivir bajo una amplia libertad, para convertir el poblado en una Logia de (Embueti); ya que son todos asociados en el Embueti, que me siguen provocando en chisterías y en insitaciones.

El caso se iba a complicar un poco más, Francisco Javier Alzina de Boschi, quién fuese en su momento auditor de la jurisdicción militar de la región ecuatorial y componente de la Comisión especial encargada de dictaminar el proyecto de Ley de Bases, sobre el régimen autónomo de la Guinea Ecuatorial, mandaba carta particular al Administrador:

Querido Peralta: Me han denunciado unos vecinos de Sácriba que ha ocurrido allí un caso de antropofagia(...)El asunto lo conoce el Jefe pero en lugar de ponerlo en tu conocimiento, se dedica a fastidiar a los vecinos que en su mayoría no le quieren(...)Como no tengo tiempo de decírtelo de palabra(...)te pongo estas líneas por si es verdad. Enterado de ello está, también según dicen, el Padre Misionero.

El caso de antropofagia había tenido lugar en el año 1944, a pesar de ello, el Cabo Bibang interrogaba a los implicados, enviando los resultados al Administrador, quién dictaba sentencia:

Visto que el hecho(...)ocurrió en el año 1944 y no existe(...)ninguna prueba y el testigo presencial(...)niega(...) que fuera carne humana; $y$ supuesto que existe un pequeño complot para destituir al jefe entre los indígenas. José Mekane, Esteban Leme y Antonio Moro, los cuales fueron quienes presentaron la denuncia en el patronato I (Patronato de Indígenas), al enterarse que iban a ser detenidos en esta Administración, por difamación y desobediencia al jefe.

Visto lo cual se acuerda imponerles dos meses de cárcel, por difamación, denuncia falsa y como que este hecho hubiese sido cierto, por encubridores ya que han transcurrido seis años sin presentar denuncia alguna.

Año 1951:

Durante este año se dan las últimas referencias al Bwiti dentro de las Palabras del Tribunal de Santa Isabel. 
La Pp82.(A.G.A.) (81/8566, Exp 82) es la más temprana, donde consta la doble denuncia del jefe de poblado de Botonos sobre un par de sucesos, cuyo protagonista era Martìn Nguema. Éste como "jefe de butî" era sujeto a doble acusación, por haber cobrado treinta y cinco pesetas, no haber curado a la joven Enriqueta Chechele de sus padecimientos "de <<ataque >>", y haberla dejado embarazada; por otro lado, también se le acusaba del uso de elementos mágicos "a fin de proceder un divorcio de los cónyuges Eyene y María".

Sentencia:

Deduzco quedar evidenciado haberse dedicado el demandado Martín Nguema a prácticas de medicinero, no resultando de las mismas víctima alguna, aunque si ha sido el causante de los temores consiguientes a tales prácticas(...)aquellas las efectuaba en mira engañosa y para sacar dinero a incautos, es condenado a sufrir SEIS meses de cárcel

La Pp393.(A.G.A.) (81/8567, Exp 393) cierra el ciclo de acusaciones contra el Bwiti, así como el proceso sobre el núcleo de Laka, donde quedaba aclarada toda la estructura del grupo para el administrador judicial. La Guardia Colonial, denunciaba que en el poblado:

Existen indígenas que se dedican a engañar a los bubis fingiendo curarles y darles buena suerte mediante la invocación del Arcángel San Miguel cobrando cantidad muy alta(...)dichos invocadores de espíritus para hacer curar y atraer la buena suerte, son Bernardo Ripen , como representante del Arcángel San Miguel y Justo Bosochi, secretario preferido del Sr Ripen; Lorenzo Toráo discípulo de los mismos.

La misma denuncia comunicaba el requisamiento de diferentes elementos rituales, además adjuntaba una lista de deudores de los denunciados que incluía los montantes de las deudas, alguna de ellas de cuantía importante para la época.

Tres días después de la denuncia de la Guardia Colonial, era enviada al administrador de justicia una carta manuscrita firmada por el Jefe del poblado, Pablo Ylepa, el Secretario Benito Sikara y la representante de "Orden del Pueblo", Ana Laerá Bojeka. Informaban de una reunión mantenida por el vecindario del pueblo, en protesta por "la costumbre de los indígenas bubis de éste, actualmente detenidos en la brigada disciplinaria”. Éstos eran, Bernardo Ripen, Justo Bosochi, Lorenzo Toráo y el hermano de Bernardo, Cecilio Ripen. Pedían la expulsión 
de la isla de los mismos, "aplicándoles la máxima pena que corresponde a sus malas costumbres, hasta para jamás contar con los cuatro como vecinos de Baney Laka, aun cuando hayan cumplido las penas que se les impongan". Estaban "indignados(...)sobre su vergonzosa costumbre de hechicería o magia negra conocida por $<<M B U T I>>$ ". Unos meses más tarde, a finales de Enero de 1952, con los reos cumpliendo condena en prisión, los mismos -Lorenzo Toráo, Bernardo Ripen, Justo Bosochi--, teniendo conocimiento de dicha reunión, escribían al administrador en busca de defensa por las consecuencias de la misma.

Comunicaban la costumbre del poblado de realizar "una adoración pagana y anticatólica, cuyos ritos y ceremonias se celebran de común acuerdo de sus habitantes mediante juramento, al objeto de maldecir cualquier vecino ó de desposeerle de sus bienes enclavados en el ámbito de dicho poblado". Si tal juramento era quebrantado, suponía la pena "de muerte" para aquellos que abandonaban los acuerdos juramentados. Ésta "medicina" llamada "Bohikot" consistía en evitar que los reprobados fuesen "partícipes de ninguna clase de sus bienes(...)ni recibir visitas de parientes y amigos ni saludo".

El miedo de los reos, bien fuese por la desposesión material, por la exclusión y el aislamiento social, o por el acto mágico en sí, quedaba patente al pedir al administrador que tomase "las medidas oportunas" para que hubiese una nueva reunión del pueblo y que dejase "sin efecto esta fatal decisión, y de ser posible, eliminar para siempre el <<Bohikot $>>$ en el poblado de Laka".

\section{Sentencia:}

Después de oídas las declaraciones de todos los demandados y testigos queda plenamente demostrado que Raimundo Eriola es el jefe absoluto de una sociedad de medicineros, pues ha sido hallado en su domicilio recetas para hacer medicina, por lo tanto: Se le condena a un año de cárcel. También queda demostrado que Bernardo Ripen era el lugarteniente de Raimundo y además reincidente de lo mismo, por lo cual se le condena también a un año. En cambio Justo Bosochi y Lorenzo Torao actuaban como ayudantes de Bernardo, por lo tanto se les condena a seis meses cada uno. 


\section{Proyección programática de un informe del Gobierno General de la Gui- nea Espańola del año 1939 sobre el Bwiti.}

La fecha del cuatro de diciembre del año de 1939 iba a marcar el tratamiento futuro de los cultos de las diferentes prácticas espirituales y religiosas no monoteístas dadas entonces en la Guinea española. El "Ilustrísimo Señor Subgobernador de la Guinea continental" (Archivo General de la Administración) (A.G.A.) (81/6262, legajo 28), hacía una petición a Gobernación General cuyo contenido reflejaba el "Asunto" de tal petición: "Informe referente a dicha secta proponiendo la pena con la muerte en la horca a los autores de asesinatos". La "secta" era el "Boeti", y los contenidos del informe serán programáticos a la hora del futuro trato hacia los diferentes cultos de la ex colonia española.

Resaltaremos tres partes de su contenido. Por un lado, traslada la información recibida desde el administrador de la zona de Kogo acerca de la amplitud y despliegue de las prácticas bwitistas en la zona, así como los temores a la mayor libertad de expresión de las mismas en el territorio vecino. Por otro lado, se pide un aumento de las medidas de represión al uso, así como una mayor libertad de aplicación de las mismas y de nuevas medidas más expeditivas. La tercera parte muestra las formas de resistencia de los indígenas desde su "medicina", y el empeño de la administración colonial de eliminar las mismas. Por último, se pide la pena de muerte para brujos o hechiceros, mostrando ya desde el mismo informe cómo a lo que se apunta es algo más que "brujería", pues en el trasfondo lo que subyace es una lucha de poder.

Las nuevas recibidas del "Señor Administrador Territorial de Kogo", abrían el comunicado, donde se enfatizaba sobre la cada vez más visible práctica del culto bwitista en la zona de su demarcación. Esta "existencia agudizada" de prácticas bwitistas era explicada "como consecuencia de la política de tolerancia que para con las sectas mantiene el Gobierno del Territorio vecino". Los temores mostrados hacia el territorio colindante no eran los únicos, pues a pesar del propio reconocimiento de no conocer caso alguno de "sacrificios humanos", y de que el culto se limitaba a "realizar la ceremonia del baile y a ingerir el jugo excitante de la planta llamada Evoga", sí mostraba temor hacia el "hechicero o brujo" por el ascendiente que tenía sobre los indígenas.

Los estados de trance extático, alcanzados con danzas e ingestión de la iboga, producían un estado modificado de conciencia en los practicantes, produciéndose 
"la sugestión máxima y la conversión del que la ingiere en un instrumento ciego del hechicero o brujo".

\section{Más medidas represivas}

Era reconocida por subgobernación la represión ejercida sobre el Bwiti, pero su efectividad no parecía ser suficientemente válida, lo que llevaba al subgobernador a pedir la aplicación de "medidas extraordinarias". Las sanciones aplicadas, tales como el encarcelamiento de los reos, parecían carecer de eficacia para reprimir las prácticas. Las medidas extraordinarias pedidas, incluían entre otras, el trabajo forzado, enfatizando su carácter de "enérgico" y medidas denominadas “(...)discrecionales(...)cuya práctica no es extraña en la colonia”. Si para Kerbo (2010), el uso de la justicia desde instancias de poder es muy común, para generar, justificar y salvaguardar asimetrías, siendo una de las herramientas al uso para los dominantes en su encuentro con los subalternos (p. 50), éste uso, tenía también en la colonia un aspecto utilitario, pues "La resolución de $<<$ palabras $>>$ tenía un efecto beneficioso suplementario para la administración colonial: facilitaba un gran número de presos que se podían emplear en los trabajos forzados" Nerín (2010:138).

\section{Resistencia nativa}

La lentitud en las tramitaciones judiciales de los sumarios, era atribuida a la gran dificultad para comprobar los casos de acusación, existiendo reticencia por parte de los indígenas a la hora de proporcionar información acerca de materias de interés reservado muchas de las veces para los iniciados. Consideramos que esto formaba parte de la propia resistencia de la población a la dominación colonial; punto reconocido desde Subgobernación : "dada la resistencia natural del indígena en aclarar extremos que conciernen al secreto de su $<<$ medicina $>>$ y que forman parte integrante de su vida". Como podemos ver, el propio administrador colonial reconoce la integración de la "medicina" dentro de la vida indígena; sin embargo, la acusación de "medicina" o "medicinero" desde la justicia colonial era algo a la orden del día, y a partir de este informe, los efectos de tales acusaciones serán mucho más virulentos y destructivos. Este tipo de acusación emitida desde las instancias judiciales, es para Balandier una parte más del proceso de "relaciones de dominación y subordinación", produciendo estas "la destrucción de las bases culturales indígenas" y la "destrucción de los modelos sociales tradicionales", estas acciones son llevadas a cabo en la sociedad colonizada por la minoría europea de la colonia, donde "esta minoría activa debe su posición dominante a 
su indiscutible superioridad material, $[\mathrm{y}]$ a un sistema jurídico establecido para mantener sus propios intereses" (1970:33).

\section{El Poder en juego y el juego del Poder}

Por último, se pedía directamente la pena de muerte por ahorcamiento de "autores directos de asesinatos, componentes de la secta y brujos de poblado", metiendo en el mismo saco a todos por igual; pero lo más importante, es que se pedía que dicho castigo tuviera lugar públicamente, en presencia del poblado, con la intención declarada :

de suprimir a tales hechiceros, de dar un ejemplo general que impresione, y de llevar al alma del indígena la tranquilidad y el convencimiento de que el poder de los brujos es limitado por el blanco si bien en ocasiones le ponen en trance de fusilar en masa (caso reciente en el Camerún) como único medio de atajar una revuelta provocada por el ascendiente indiscutible de los hechiceros en la masa indígena.

La petición de castigo público no es más que un movimiento dentro de un juego en el que "Las creencias pueden ser manipuladas tanto por los individuos que luchan por el poder, como por los que apoyan (o niegan su apoyo) a los contendientes" Lewellen(2009:101); y donde la imagen minusvalorada de brujos y hechiceros por parte de la administración colonial, no es otra, que su propósito de eliminar un competidor seguro, con influjo y ascendencia suficiente sobre sus correligionarios para llegar a provocar "una revuelta" como la aludida del Camerún, donde la dominación colonialista y sus métodos violentos quedan al descubierto al tener que poner sus cartas boca arriba mencionando un fusilamiento masivo.

Diez días después de la petición de libertades plenas para castigar, se hacía llegar respuesta. Ésta no será otra que una patente de corso, desde la cual ejercer impunemente la represión contra el Bwiti y sus practicantes. La comunicación al Gobierno general de "la existencia generalizada de $<<$ Boeti $>>$ en la demarcación de Kogo", así como la petición de "más eficaces castigos para corregirlas", tiene como respuesta, permiso en el cual "viene en aprobar su propuesta autorizando a ese Subgobierno para tomar las medidas extraordinarias que estime oportunas para su represión.” 


\section{De-velando el documento}

A modo de iceberg, el documento estudiado tiene un trasfondo de tamaño y complejidad considerable. Para sacarlo a la luz, vamos a enfatizar tres ámbitos, por un lado, la relación intrínseca mostrada por Lewellen (2009) entre política y fenómeno religioso, tomando nosotros en consideración, creencias, representaciones simbólicas, y prácticas. Por otro lado, tal relación la entendemos dentro de un ámbito más amplio como es el de la manipulación simbólica, expuesta en Cantón (2009), y expresada ésta a través de la construcción social del estigma. Por último, el uso utilitario desde las instancias de la justicia colonial, del proceso de estigmatización.

El manejo de tal proceso, queda cristalizado en este caso en forma de documento oficial e institucionalizado bajo la forma de acusación de brujería o hechicería. La petición de la Subgobernación hace clara referencia, por un lado, a nuevas formas de representación simbólica, así como de prácticas ejercidas por los nativos y lideradas por los acusados de brujos. Creemos que a este respecto hay dos preguntas para guiarnos. ¿Por qué este bullir de nuevos cultos y prácticas religiosas?, ¿por qué la petición de mayor represión por parte de la administración colonial?.

Para Nerín (2010), hacía diez años que la conquista del territorio del Muni se había consolidado y había eliminado las hostilidades, pero a su vez, el mundo de vida de los nativos había sido desestructurado. Los sistemas tradicionales de parentesco, solidaridades, y el antes potente culto Biere, habían sido destruidos. Gran parte de estas nuevas prácticas, y el Bwiti en particular, pueden ser vistos desde la perspectiva aportada por Lewellen, para quien las superestructuras religiosas, no son sólo una encarnación de pasividad para el desarrollo de la propia acción política. La disputa por el poder, también es llevada al campo de las creencias, siendo estas manipuladas, y sirviendo de apoyo, tanto para los que pretenden el poder como para sus contrincantes (2009:101).

La traducción desde la administración colonial del Bwiti a términos políticos, provocó una defensa de medidas represivas más eficaces para contrarrestar las resistencias. Esta pugna por el poder, genera muchas de las veces violencias desde el propio orden establecido sobre los cultos no hegemónicos, siendo las mismas fruto tanto de la interrelación político-religiosa, como del proceso de construcción estigmática. Cantón (2009:228) señala "el carácter construido del estigma que etiqueta las prácticas religiosas antihegemónicas, sobre las que 
comúnmente se realiza y divulga una lectura en clave de alarma social". Alarma social dada por las atribuciones otorgadas a los nuevos practicantes de "peligrosos", "extraviados", y en nuestro caso concreto de "brujos", "hechiceros", o simplemente de practicar el Bwiti, para quienes se pide, "pena de muerte por horca", "persecución y castigo" y "trabajos forzados enérgicos", incluida la tentación de "fusilar en masa". Alarma social y peticiones que a partir de 1939 de manera programática fueron posteriormente aplicadas.

El incremento de represión ejercido sobre el Bwiti, que nosotros opinamos viene dado de forma programática, ya había sido detectado anteriormente. La creciente presión judicial sobre el Bwiti en los 40's es mostrada por Sánchez Molina (2011) :

Esta presión incide en la acumulación de sumarios que contra estos seguidores del movimiento [se refiere al Bwiti] se levantan en los tribunales de la colonia; sobre todo, durante la década de 1940, alcanzando su episodio más trágico en 1948, cuando se condena a la horca a siete banyis (pp. 145-146).

\section{Conclusiones}

Dado el debate habido, dentro y fuera de la academia, sobre si hubo Bwiti o no en Fernando Poo, hemos visto en las Palabras más tempranas, cómo inicialmente sí que se practicó, al menos por los Braceros que llevaban el culto con ellos mismos y que dan origen a su implantación isleña. Los primeros representantes del culto eran de la zona continental, Bata, Gabón, etc, pero lo que no tenemos claro todavía, a pesar de referencias judiciales como las del núcleo de Laka, es la continuidad del Bwiti entre los Bubis. Para Aranzadi (declaración oral en el II seminario internacional sobre Guinea Ecuatorial), el Bwiti de la etapa estudiada tiene una característica fundamental: no es un culto de posesión. Desde la información de las Palabras, en el núcleo de Laka había dos ramas, la de los espíritus y la de los medicineros. Esto nos adentra en la incertidumbre, ya que podría ser Mbiri, un culto paralelo que coincide con el Bwiti en la ingestión de Iboga y el uso del arpa Ngombi pero en el que sí se da la posesión. 
Hemos mostrado la declaración de intenciones represivas plasmadas en el documento del año 1939 así como su faceta programática en la aplicación de las mismas en las Palabras vistas desde 1940 hasta 1951. También nos preguntamos por qué desde 1951 hasta 1962 no hay casos abiertos de represión bwitista, cuando sí que los hay, y no pocos de otros cultos. ¿Desapareció el Bwiti de la isla, se había transformado, había perdido su inspiración política, o había cambiado la perspectiva del colonizador?.

También queda clara la naturaleza de las actuaciones represivas en sus diferentes formas de expresión presentes en el diálogo documental. Se muestran bajo forma de "agresión física", "represión jurídica", "penalización económica", "asimetría judicial" "terror", y siendo ejercidas algunas veces por las propias autoridades oficiales y otras desde el ámbito civil. Estas formas alimentaban la violencia política, institucional y estructural, presentada esta última bajo una forma de distribución diferencial y desequilibrada de poder visiblemente institucionalizada en los medios de represión jurídicos y de violencia legitimada.

Los palos, la Brigada disciplinaria, la cárcel, las multas y los requisamientos, pueblan las Palabras como formas de represión. Hay una que nos parece paradójica: la expulsión y deportación de braceros. El Administrador colonial, debía tener fuertes temores (expresados abiertamente en el documento de 1939) como para permitirse el lujo de expulsar braceros de una isla siempre ávida de mano de obra durante todo el periodo colonial. ¿Qué parte del Bwiti atemorizaba?.

Hemos visto también cómo la represión del Bwiti, en un momento dado, se ejerce a lo largo del tiempo y el espacio sobre ciertos clanes familiares. Hay una serie de "apellidos" que aparecen una y otra vez, mostrando una continuidad en la persecución de ciertas familias. En el núcleo de Laka, el grupo familiar de los Ripen son intervenidos por la justicia una y otra vez, siendo objeto de acoso dilatado en el tiempo. Otras dos familias que podemos incluir dentro de esta continuidad, son los Opo y los Siale, ambos muchas veces relacionados con varios de los casos expuestos.

Llegados a este punto, vemos que los interrogantes son más numerosos que las certezas, lo que invita a nuevas investigaciones y aportes documentales, desde un enfoque interdisciplinar que nos permita acercamientos fructíferos a un fenómeno tan dinámico como es el Bwiti. 


\section{Agradecimientos}

El presente trabajo forma parte de los frutos del proyecto de referencia HAR2012-34599 "Lo que sabemos, ignoramos, inventamos y deformamos acerca del pasado y presente de Guinea Ecuatorial. Revisión crítica multidisciplinar y nuevas vías de investigación”.

\section{Referencias bibliográficas y documentales}

ARANZADI, J (2013). "Conquistadores y fugitivos (el Bosque y el Mal para Pigmeos y Fang)”. En J. Aranzadi y P. Moreno (Coord.), Perspectivas antropológicas sobre Guinea Ecuatorial. (pp. 69-92). Madrid. UNED.

ARCHIVO GENERAL DE LA ADMINISTRACIÓN (A.G.A.). (1939). (81/6262: legajo 28). Alcalá de Henares.

-A.G.A. (1940) (81/8533, Exp 380). Alcalá de Henares.

-A.G.A. (1940) (81/8533, Exp 814). Alcalá de Henares.

-A.G.A. (1941) (81/8533, Exp 419). Alcalá de Henares.

-A.G.A. (1941) (81/8540, palabra penal 809). Alcalá de Henares.

-A.G.A.(1941) (81/8533, Exp 819). Alcalá de Henares.

-A.G.A. (1942) (81/854, palabra penal 85). Alcalá de Henares.

-A.G.A. (1944) (81/8550, palabra penal 558). Alcalá de Henares.

-A.G.A. (1946) (81/8553, legajo 42). Alcalá de Henares.

-A.G.A. (1947) (81/8555, legajo penal 71). Alcalá de Henares.

-A.G.A. (1947) (81/8556, legajo penal 174). Alcalá de Henares.

-A.G.A. (1947) (81/8556, legajo penal 178). Alcalá de Henares.

-A.G.A. (1949) (81/860, legajo 229). Alcalá de Henares.

-A.G.A. (1950) (81/8563, Exp 360). Alcalá de Henares.

-A.G.A. (1950) (81/8565, Exp 636). Alcalá de Henares.

-A.G.A. (1951) (81/8566, Exp 82). Alcalá de Henares. 
-A.G.A. (1951) (81/8567, Exp 393). Alcalá de Henares.

BALANDIER, G (1970). Sociologie actuelle de l'Afrique Noire. París: Presses Universitaires de France.

CANTÓN, M (2009). La razón hechizada. Teorias antropológicas de la religión. Barcelona: Ariel.

FERNÁNDEZ, J (1982). Bwiti. An Ethnography of the Religious Imagination in Africa. New Jersey: Princeton University Press.

FERNÁNDEZ, L. C.M.F (1927, 10 de Julio). La magia entre los indígenas de nuestro continente. La guinea española, Núm 644, 10-11.

KERBO, R. H (2010). Estratificación social y desigualdad. El conflicto de clase en perspectiva histórica comparada y global. Aravaca: Mc Graw Hill.

LEWELLEN, T (2009). Introducción a la antropología politica. Barcelona: Bellaterra.

MARTÍN DEL MOLINO, A (1993). Los Bubis. Ritos creencias. Madrid: Labris 54, SL.

NERÍN, G (1998). Guinea Ecuatorial, historia en blanco y negro. Hombres blancos y mujeres negras en Guinea Ecuatorial (1843-1968). Barcelona: Península.

-(2010). La última selva de España. Antropófagos, misioneros y guardias civiles. Crónica de la conquista de los Fang de la Guinea Española, 1914-1930. Madrid: Libros de la Catarata.

OKENVE, E (2007). Equatorial Guinea 1927-1979. A New African Tradition. Tesis doctoral, University of London, School of Oriental and African Studies, London, Inglaterra.

SÁNCHEZ MOLINA, R (2011). El Pamue imaginado. Madrid: Universidad Nacional de Educación a Distancia.

TESSMANN, G (2003[1913]). Los Pamues (Los Fang). Alcalá de Henares: Universidad de Alcalá, servicio de publicaciones.

VECIANA, A (1958). La secta del Bwiti en la Guinea Española. Madrid: IDEA. 